\title{
Upon the Delivery Properties of a Polymeric System Based on Poly(2-Hydroxyethyl Methacrylate) Prepared with Protective Colloids
}

\author{
Loredana E. Nita ${ }^{1}$, Aurica P. Chiriac ${ }^{1}$, Manuela Nistor ${ }^{1}$, Tatiana Budtova ${ }^{2 *}$ \\ 1“Petru Poni” Institute of Macromolecular Chemistry, Iasi, Romania; ${ }^{2}$ Centre de Mise en Forme des Matériaux, Mines ParisTech, \\ UMR CNRS 7635, Sophia-Antipolis, France. \\ Email: *1nazarie@yahoo.co.uk
}

Received June $30^{\text {th }}, 2013$; revised July $30^{\text {th }}, 2013$; accepted August $15^{\text {th }}, 2013$

Copyright (C) 2013 Loredana E. Nita et al. This is an open access article distributed under the Creative Commons Attribution License, which permits unrestricted use, distribution, and reproduction in any medium, provided the original work is properly cited.

\begin{abstract}
A comparative study related to the preparation of poly(2-hydroxyethyl methacrylate) (pHEMA) through radical polymerization process in the presence of three different protective colloid substances, respectively poly(vinyl alcohol) (PVA), $\beta$-cyclodextrin, or poly(aspartic acid) (PAS), is presented. The dependence of the thermal behavior of the polymers as well as their morphological aspect, on the protective colloids used in synthesis was evidenced by polymers characterization. It is also demonstrated that the swelling capacity is dependent on the protective colloid variant present during the pHEMA preparation. This behavior induces as well interdependence on the ability to load bioactive compounds onto the polymeric matrices. The distribution of the indomethacin (INN), as model drug, into the pHEMA network was put into evidence by near infrared chemical imaging (NIR-CI), a non-destructive technique and with its correspondingly statistical analysis.
\end{abstract}

Keywords: Biocompatible Polymers; Polymer Network; $\beta$ Cyclodextrin; Poly(Aspartic Acid)

\section{Introduction}

Methacrylic polymers and copolymers are widely used for various medical and pharmaceutical applications. Among them poly(2-(hydroxyethyl) methacrylate) (pHEMA) is favored for preparing intraocular lenses, and microbeads for vascular embolization, immobilization of cells, enzymes or pharmacological drugs. The hydroxyethyl pending groups of the polymer ensure high hydrophilicity, good biocompatibility and the possibility to prepare pHEMA in the form of a hydrogel [1,2].

As it is well known, the heterogeneous free radical polymerization process involves the relative solubilization of the hydrophobic monomers in water for example by an oil-in-water emulsifier, followed by the initiation reaction with either a water insoluble initiator or an oilsoluble initiator [3]. During polymerization an extremely large oil-water interfacial area is generated as the particle nuclei form, which is growing in size with the progress of the process. Effective stabilizers such as ionic and/or

${ }^{*}$ Corresponding author.

Member of the European Polysaccharide Network of Excellence (EPNOE), www.epnoe.eu. non-ionic surfactants and protective colloid, which can be physically adsorbed or chemically incorporated onto the particle surface, are required to prevent the interactive latex particles from coagulation. Thus, satisfactory colloidal stability is achieved by the electrostatic stabilization mechanism [4], the steric stabilization mechanism [5] or both. The formation of stable colloidal particles during polymerization of 2-hydroxyethyl methacrylate, as water-soluble monomer but insoluble homopolymer, requires a proper choice of initiator and/or surfactant. Thus, stable latex products were produced from 2-hydroxyethyl methacrylate, only if hydrophobic initiators (e.g. AIBN or benzoyl peroxide) in combination with alkyl sulfate with the alkyl chain length greater than 10 or surface-active initiators (e.g. 2, 20-azobis(N-20-methylpropanoyl-2-amino-alkyl-1)-sulfonate) with the alkyl chain length greater than eight were used [6].

The preparation of poly(2-hydroxyethyl methacrylate) latex with adequately high solid content is not easy at all compared to the hydrogel preparation, since the monomer exhibits an extremely high aqueous solubility and the latex faces coagulation easily [7]. The polymerization 
of 2-hydroxyethyl methacrylate (HEMA), using a series of initiators (2,2'-azobisisbutyronitrile, 2,2'-azobis-(2amidinopropane) dihydrochloride, 4,4'-azobis(4-cyanopentanoic acid) (ACPA), 1,1'-azobis(cyclohexane carbonitrile)) and using either sodium lauryl sulfate (SLS) as emulsifier or a mixture of SLS and poly(vinyl pyrrolidone) (PVP) as tensioactive system, has been already reported [8].

The goal of our investigation was to study the pHEMA characteristics, especially from the viewpoint of its capacity of coupling bioactive substances, after preparing the polymer through radical dispersion polymerization in the presence of ACPA as initiator and using classic tensioactive - sodium lauryl sulfate (SLS) - in tandem with one of the following protective colloids: poly(vinyl alcohol) (PVA), or $\beta$-cyclodextrine (CD) or poly(aspartic acid) (PAS).

It is known for the beneficial effect of PVA as protective colloid, which limits the flocculation of the interactive particles, restrains the coalescence between monomer droplets and the polymer particles, and also, improves generally the performance of the latex characteristics.

$\mathrm{CD}$ was also tested in the polymerization processes of the extremely hydrophobic dodecyl methacrylate or octadecyl methacrylate to study the role of $\beta$ cyclodextrine in the nucleation and growth of particle nuclei and transport of those monomer molecules from monomer droplets to the growing latex particles, as far as CD forms inclusion with the guest species, and thus, increases the water solubility of the hydrophobic compounds [9-12].

PAS belonging to the family of synthetic polypeptides is a typical biocompatible, biodegradable water-soluble polymer with dispersing activity, and it can be used as dispersant, antiscalant, or superabsorber, for home detergents, water treatment chemicals, and oil field treatment additives, for a variety of organic and inorganic solids and scales dispersal, and in medicines, cosmetics, and food. It is considered to be a sustainable, environmentally compatible chemical product and its biodegradability makes it particularly valuable from the viewpoint of environmental acceptability and waste disposal $[13,14]$. Its use as protective colloid will induce the increase of the absorbent character as well as biocompatibility and biodegradability for the system.

The thermal stability of the synthesized polymers was evaluated and the polymer network morphology was examined by SEM investigations. The new polymeric structures were also tested from the viewpoint of their capacity to be loaded with a bioactive compound. Thus, the swelling degree of the pHEMA was determined related to the $\mathrm{pH}$ and at two temperature values (at room and respectively physiological temperature). The ability of pHEMA to be loaded with indomethacin as model drug, and the release of the bioactive compound from the polymeric network, were also evaluated.

\section{Experimental Part}

\subsection{Materials}

2-Hydroxyethyl Methacrylate (HEMA) (from Fluka, purity $>96 \%$ ) was purified by passing through an inhibitor removal column. The tensioactive substance, sodium lauryl sulfate (SDS) $\left(\mathrm{C}_{12} \mathrm{H}_{25} \mathrm{O}_{4} \mathrm{SNa}\right)$, was purchased from Sigma-Aldrich. Poly(aspartic acid) (PAS) $\left(\mathrm{M}_{\mathrm{w}}=15000\right)$ was synthesized in our laboratory as it was detailed in the reference [14] (hydrolysis of polysuccinimide). $\beta$-cyclodextrine (CD) $\left(\mathrm{M}_{\mathrm{w}}=1135\right.$, purum, $\geq 99 \%$ ), from Sigma-Aldrich, and poly(vinyl alcohol) (PVA), from Oriental Chemical Industry $\left(\mathrm{M}_{\mathrm{w}}=120000\right.$ $\mathrm{Da}$, hydrolysis degree $=88$ ), were used without further purification. The radical initiator 4, 4'-azobis(cyanopentanoic acid) (ACPA) (from Fluka, 98\%) was used also without further purification. The water used in all experiments was purified using an Ultra Clear TWF UV System.

\subsection{Polymer Compounds Preparation}

\subsubsection{Polymerization Process}

The radical polymerization processes were conducted under nitrogen atmosphere, in a temperature bath at $80^{\circ} \mathrm{C}$, with a mechanical stirring rate of $180 \mathrm{rpm}$. The polymerization formulations are presented in Table 1.

After synthesis the polymeric particles were precipitated three times with methanol and finally freeze-dried by lyophilization for $24 \mathrm{~h}$.

\subsubsection{Polymer Matrices Loading with Indomethacin}

In order to evaluate the capacity of the networks of the synthesized polymers to be loaded with drug, and to determine as well the release behavior, Indomethacin (INN), as a model drug, was loaded into the pHEMA ${ }_{\mathrm{PVA}}$, pHEMA $_{\mathrm{PAS}}$, and respectively $\mathrm{pHEMA}_{\mathrm{CD}}$ polymeric ma-

Table 1. Polymerization recipes (substances are given in grams).

\begin{tabular}{cccc}
\hline \multirow{2}{*}{ Component } & \multicolumn{3}{c}{ System } \\
\cline { 2 - 4 } & PHEMA $_{\text {PAS }}$ & PHEMA $_{\text {PVA }}$ & PHEMA $_{\mathrm{CD}}$ \\
\hline HEMA & 8 & 8 & 8 \\
ACPA (initiator) & 0.05 & 0.05 & 0.05 \\
SLS (tensioactive) & 0.267 & 0.267 & 0.267 \\
PAS & 0.267 & 0 & 0 \\
PVA & 0 & 0.267 & 0 \\
CD & 0 & 0 & 0.267 \\
Water & 100 & 100 & 100 \\
\hline
\end{tabular}


trices. The drug powder was dissolved in ethanol/phosphate buffer solution $(\mathrm{pH}=7.2)$ to obtain a concentration of $\mathrm{c}=1.9005 \times 10^{-5} \mathrm{~mol} / \mathrm{ml}$. Then the polymers were immersed in this solution and let to swell till equilibrium (the ratio INN/copolymer was about $1 / 10 \mathrm{wt} \%$ ). The swollen drug-loaded samples were then dried at ambient temperature for several days until the prepared particles had constant mass. The particles were then freeze-dried to obtain the resultant drug-loaded network to use them in the release experiments.

\subsection{Polymers and Polymer Composites Characterization}

\subsubsection{Polymers FTIR Spectra}

Polymers FTIR spectra were recorded on a Vertex Brucker Spectrometer in an absorption mode ranging from $4000 \mathrm{~cm}^{-1}$ to $400 \mathrm{~cm}^{-1}$ (Figure 1). The polymeric samples were grounded with potassium bromide $(\mathrm{KBr})$ powder and compressed into a disc to analysis. Spectra were acquired at $4 \mathrm{~cm}^{-1}$ resolution as an average of 64 scans. The registered spectra confirms pHEMA achievement small recorded differences being attributed on the used protective colloids. Thus, $v(\mathrm{O}-\mathrm{H})$ stretching vibration in HEMA is observed in the $3400-3500 \mathrm{~cm}^{-1}$ range as broad absorptions, and the strong band at $2950 \mathrm{~cm}^{-1}$ and $\sim 2970 \mathrm{~cm}^{-1}$ is attributed to the $v(\mathrm{C}-\mathrm{H})$. Another strong band at $\sim 1730 \mathrm{~cm}^{-1}$ is assigned to $v(\mathrm{C}=\mathrm{O})$ group, at $2940 \mathrm{~cm}^{-1}$ to $v(\mathrm{C}-\mathrm{H})$ stretching of $-\mathrm{CH}_{3}$, and also at $\sim 1270 \mathrm{~cm}^{-1}$ to $v(\mathrm{C}-\mathrm{O})$ stretching vibration.

\subsubsection{Thermal Analysis}

The thermal characterization of the polymers was performed on a Jupiter STA 449 F1 (Netzsch) simultaneous TGA/DSC device calibrated with high purity chemicals, respectively with standard indium, tin, zinc and aluminum. The samples were maintained in a controlled

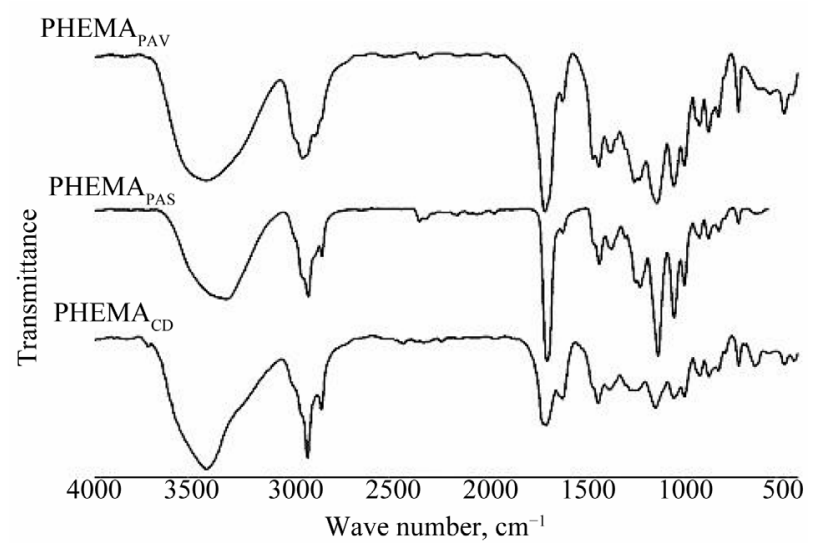

Figure 1. FTIR spectra of the polymers synthesized according to recipes from Table 1. humidity atmosphere provided by the presence of $\mathrm{CaCl}_{2}$ inorganic salt. $7.5-8 \mathrm{mg}$ samples were heated in open $\mathrm{Al}_{2} \mathrm{O}_{3}$ crucible under $50 \mathrm{ml} \cdot \mathrm{min}^{-1}$ nitrogen flow rate. The runs were performed in the dynamic mode from room temperature up to $600^{\circ} \mathrm{C}$ with a heating rate of $10^{\circ} \mathrm{C} \cdot \min ^{-1}$.

\subsubsection{SEM Studies}

were performed on samples fixed by means of colloidal copper supports. The samples were covered by sputtering with a thin layer of gold (EMITECH K 550×). The coated surface was examined by using an Environmental Scanning Electron Microscope (ESEM) type Quanta 200 operating at $30 \mathrm{kV}$ with secondary electrons in high vacuum mode.

\subsubsection{Swelling Studies}

Dynamic swelling measurements were performed in buffer solutions at two $\mathrm{pH}$ values, 2.4 and 7.4, and each at two temperatures: $24^{\circ} \mathrm{C}$ and respectively $37^{\circ} \mathrm{C}$. The amount of the adsorbed solution was monitored gravimetrically: the swollen particles were regularly extracted from the swelling medium, wetted on the surface, weighed and placed again in the same bath. The measurements were continued until the constant weight was reached for each studied sample. The degree of swelling (Q) was calculated as follows:

$$
\mathrm{Q}, \%=\left[\left(\mathrm{M}(\mathrm{t})-\mathrm{M}_{0}\right) / \mathrm{M}_{0}\right] * 100 \%
$$

where $M(t)$ is the weight of the swollen particles at time $t$ and $\mathrm{M}_{0}$ is the weight of the sample before swelling. All the swelling experiments were performed in triplicate.

\subsection{Loading Evaluation}

The evaluation of the drug distribution in the polymeric matrix was made using near infrared chemical imaging (NIR-CI) technique and the correspondingly statistical analysis. The original image data sets of samples were collected by a completely integrated Chemical Imaging Workstation from SPECIM Spectral Imaging Ltd (Finland). Acquisition of spectral lines was made on the wavelength range starting from $1100 \mathrm{~nm}$ to $2500 \mathrm{~nm}$. Images with $320 \times 640$ pixels were recorded with a spectral camera (NIR model based on an ImSpector N17E imaging spectrograph).

Data pre-processing, preliminary visualization and the proper characterization were performed using Evince program (UmBio, Sweden), a software package designed for visualization and analysis of hyper spectral image cubes. The contrast in the chemical images is compared by methods using the intensity of a single wavelength, the peak-height ratio of two wavelengths, the correlation coefficient with a reference spectrum and the principal 
component analysis (PCA). The correlation coefficient method was also compared with the partial least squares (PLS-DA) regression for further homogeneity investigations.

\subsubsection{In Vitro Controlled Release of Indomethacin from Polymer Matrices}

Studies concerning the INN release have been carried out in vitro using the USP padle (apparatus II) method with a dissolution tester (ERWEKA Dissolution Testers) at 50 $\mathrm{rpm}, \mathrm{pH}=7.4$ and $37^{\circ} \mathrm{C}$ temperature. The dried samples (approx. $200 \mathrm{mg}$ particles of each formulation) loaded with INN were immersed in the phosfate buffer solution. $700 \mathrm{~mL}$ dissolution medium used for the determination contains potassium dihydrogen phosphate $\left(\mathrm{KH}_{2} \mathrm{PO}_{4}, 0.2\right.$ $\mathrm{M})$, monohydrogen phosphate $\left(\mathrm{K}_{2} \mathrm{HPO}_{4}, 0.2 \mathrm{M}\right)$ and water. Time was recorded as soon as the particles were put into the dissolution vessels. For the drug release analysis $2 \mathrm{ml}$ sample solution were withdrawn from vessel at appropriate time intervals $(1,3,5,10,15,20,25$, $30,40,60,90,120,150,180,240,360$ and after that at each 120 minutes until 1600 minutes). $2 \mathrm{ml}$ of fresh phosphate buffer solution, heated to $37^{\circ} \mathrm{C}$, was immediately added to the dissolution medium for compensating the sampling. The dissolution study was carried out for three samples from each formulation. The amount of the released INN was determined spectrophotometrically (Perkin Elmer spectrophotometer) at $319 \mathrm{~nm}$.

\section{Results and Discussions}

\subsection{Thermal Analysis}

The evolution of the thermal decomposition of the polymers synthesised with different protective colloids is illustrated in Figure 2. The registered differences are attributed to the influence of the protective colloids upon thermal characteristics of the polymers synthesised in their presence. For pHEMA $\mathrm{CD}_{\mathrm{CD}}$ two stages of decomposition were registered between $167^{\circ} \mathrm{C}$ to $223^{\circ} \mathrm{C}$ and respectively from $321^{\circ} \mathrm{C}$ to $421^{\circ} \mathrm{C}$. The weight loss registered at the beginning of the decomposition process is attributed to the loss of the water of inclusion inside the cavity of $\mathrm{CD}$, phenomena also reported by other authors [15]. The pHEMA ${ }_{P A S}$ and pHEMA ${ }_{P V A}$ samples have as well two stages of decomposition, but the first one is not as evident as in case of pHEMA $\mathrm{CD}_{\mathrm{CD}}$ samples. The specific parameters corresponding to the main decomposition step, the second one, of the studied samples are presented in Table 2. These data confirm the influence of the protective colloid on the stability of the pHEMA.

The thermal stability of polymers can be ordered as follows: PHEMA $_{\mathrm{CD}}<$ PHEMA $_{\mathrm{PAS}}<$ PHEMA $_{\mathrm{PVA}}$. The

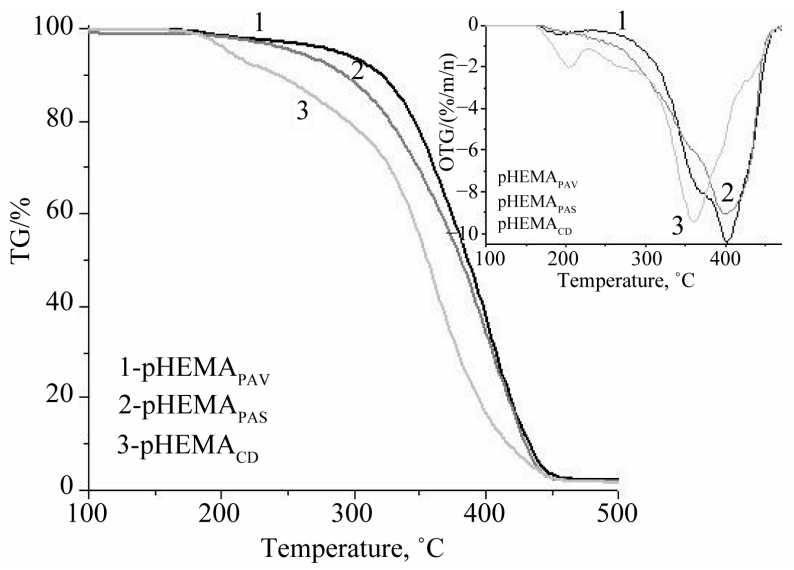

Figure 2. TG and DTG curves characterizing the thermal decomposition behaviour of the synthesized polymers.

Table 2. Thermal characteristics of the synthesized samples.

\begin{tabular}{ccccc}
\hline \multirow{2}{*}{ Polymers } & \multicolumn{3}{c}{ The main decomposition step } & \multirow{2}{*}{$\Delta \mathrm{W}, \%$} \\
\cline { 2 - 4 } & $\mathrm{T}_{\text {onset }},{ }^{\circ} \mathrm{C}$ & $\mathrm{T}_{\text {max }},{ }^{\circ} \mathrm{C}$ & $\mathrm{T}_{\text {end set, }}{ }^{\circ} \mathrm{C}$ & \\
\hline PHEMA $_{\mathrm{PVA}}$ & 252 & 402 & 472 & 98.1 \\
PHEMA $_{\mathrm{PAS}}$ & 232 & 400 & 465 & 98.4 \\
PHEMA $_{\mathrm{CD}}$ & 228 & 360 & 465 & 98.4 \\
\hline
\end{tabular}

$\mathrm{T}_{\text {onset: }}$ Temperature of the beginning decomposition; $\mathrm{T}_{\max }$ : Temperature at maximum decomposition rate; $T_{\text {endset: }}$ Temperature at the end of decomposition process; $\Delta \mathrm{W}$ : Total weight loss percentage at the end steps.

differences registered in the thermal stability are considered to be in relation with surfactants structure, practically with the number of physical bonds, especially hydrogen bonds, performed between pHEMA and the tested protective colloids. In this context, the molecular mass of the protective colloids is as well an important factor in generating intermolecular interactions with the chains of the new synthesised polymer compound. Thus, the best thermal stability of the pHEMA $\mathrm{PAV}_{\mathrm{P}}$ is in agreement with the PAV molecular weight of about 70,000 , being followed by pHEMA $A_{P A S}$ with $\mathrm{M}_{\mathrm{PAS}} \sim 15,000$ and finally by $\mathrm{pHEMA}_{\mathrm{CD}}$.

\subsection{SEM Studies}

Information concerning the morphology of the studied polymeric samples are obtained by SEM studies and are presented in Figures 3(a)-(c). There are clear differences between the polymers morphology stabilized by PVA (Figure 3(a)) or CD or PAS as protective colloid (Figures 2(b) and (c)). Thus, an aspect rather porous presents pHEMA $_{\mathrm{PVA}}$, while pHEMA $_{\mathrm{CD}}$ and pHEMA $_{\mathrm{PAS}}$ exhibit a more uniform aspect as self-assembled honeycomb nanofibers $\left(\mathrm{pHEMA}_{\mathrm{PAS}}\right)$ or lacing nanofibers $\left(\mathrm{pHEMA}_{\mathrm{CD}}\right)$. Also, the pore size decreases from about $17 \mu \mathrm{m}$ for PHEMA $_{\mathrm{PVA}}$ to $\sim 3 \mu \mathrm{m}$ for PHEMA $_{\mathrm{CD}}$ and $\sim 2 \mu \mathrm{m}$ for 


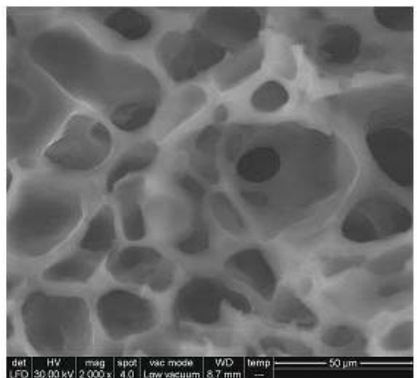

(a)

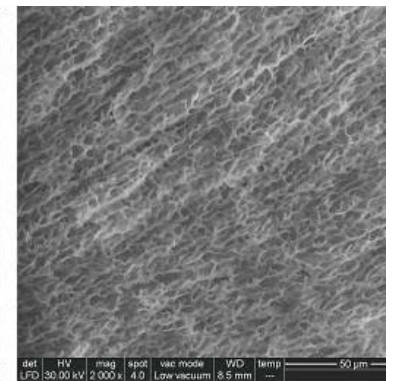

(b)

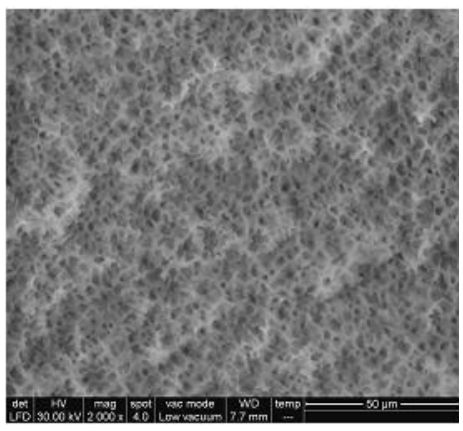

(c)

Figure 3. Comparison between PHEMA ${ }_{\text {PVA }}$ (a), PHEMA (b), PHEMA $A_{C D}$ polymers morphology (SEM micrographs at 2000 $\times$ ).

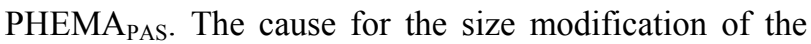
network meshes was attributed to the molecular weights of the used protective colloids and to their specific intermolecular interactions with the pHEMA chains [6].

\subsection{The Swelling Behavior}

It is well known the hydrophobic character of pHEMA. At the same time, when the polymer is subjected to water it swells due to the hydrophilic pendant groups. It is expected as the protective colloid type, used for the PHEMA synthesis, to influence as well the capacity of water absorption.

The swelling kinetic of the polymeric particles related on the swelling conditions, respectively at two $\mathrm{pH}$ values (2.4 and 7.2) and correspondingly at two temperatures $\left(24^{\circ} \mathrm{C}\right.$ and $\left.37^{\circ} \mathrm{C}\right)$, is illustrated in Figure 4. The highest swelling capacity was recorded for pHEMA $_{\text {PAS }}$ sample, followed by PHEMA ${ }_{\mathrm{CD}}$, while the lowest swelling be-

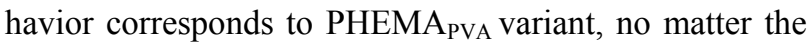
swelling conditions are (Table 3 ). The swelling behavior of pHEMA $\mathrm{AAS}_{\mathrm{P}}$ is justified by the superabsorbent and polyelectrolyte character of PAS, the intervened electrostatic forces contributing to the improvement of the polymer swelling capacity. Regarding the pHEMAPVA swelling behavior it is justified by the hydrogen bonds come along PAV and pHEMA polymer chains (Figure 5) into the detriment of bonds between pHEMA and solvent.

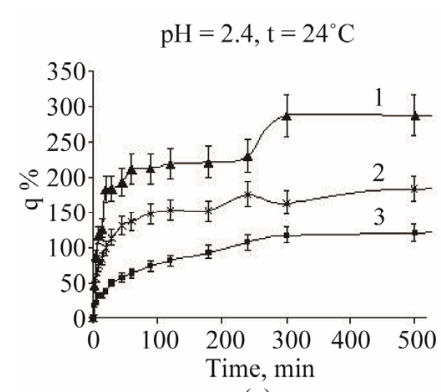

(a)

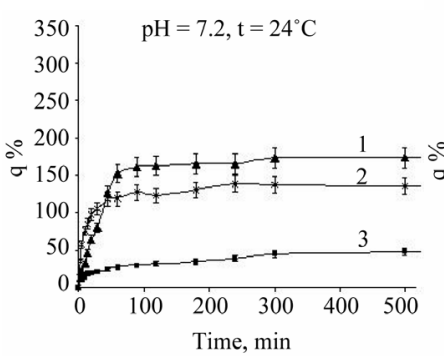

(c)

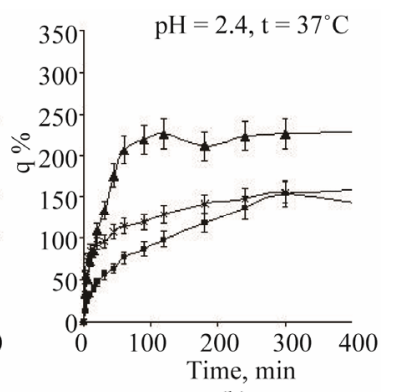

(b)

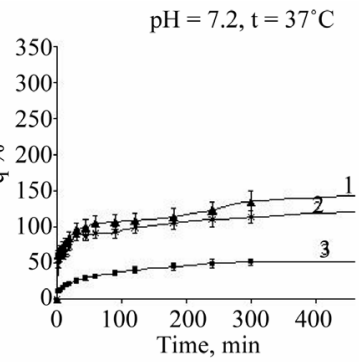

(d)
Figure 4. Swelling behavior of the PHEMA polymers related on the $\mathrm{pH}$ and temper variation: (a) $\mathrm{pH}=2.4, \mathrm{t}=24^{\circ} \mathrm{C}$; (b) $\mathrm{pH}=2.4, \mathrm{t}=37^{\circ} \mathrm{C}$; (c) $\mathrm{pH}=7.2, \mathrm{t}=24^{\circ} \mathrm{C}$; (d) $\mathrm{pH}=7.2, \mathrm{t}$

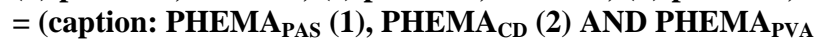
(3)).

Table 3. The swelling degree related on the conditions of determination.

\begin{tabular}{ccccc}
\hline \multirow{2}{*}{ Samples } & \multicolumn{4}{c}{ Equilibrium swelling degree, \% } \\
\cline { 2 - 5 } & $\begin{array}{c}\mathrm{pH}=2.4 ; \\
\mathrm{t}=24^{\circ} \mathrm{C}\end{array}$ & $\begin{array}{c}\mathrm{pH}=2.4 ; \\
\mathrm{t}=37^{\circ} \mathrm{C}\end{array}$ & $\begin{array}{c}\mathrm{pH}=7.2 ; \\
\mathrm{t}=24^{\circ} \mathrm{C}\end{array}$ & $\begin{array}{c}\mathrm{pH}=7.2 ; \\
\mathrm{t}=37^{\circ} \mathrm{C}\end{array}$ \\
\hline PHEMA $_{\mathrm{PAV}}$ & 117 & 155 & 45 & 52 \\
PHEMA $_{\mathrm{PAS}}$ & 300 & 226 & 173 & 145 \\
PHEMA $_{\mathrm{CD}}$ & 184 & 155 & 137 & 124 \\
\hline
\end{tabular}

The swelling behavior of pHEMA $\mathrm{PVA}_{\mathrm{A}}$ is improved in acidic medium both at room temperature and at $37^{\circ} \mathrm{C}$. The most sensitive sample is HEMA $_{\text {PAS }}$, its behavior at swelling being slightly decreased with the increase of the temperature in acid and neutral medium. Thus, swelling is two times smaller at $37^{\circ} \mathrm{C}$ comparing with the room temperature. At the same time, $\mathrm{pHEMA}_{\mathrm{CD}}$ is practically not sensitive either to $\mathrm{pH}$ or temperature, in the studied intervals.

In the context of the obtained results the higher swelling behaviour registered at the acidic $\mathrm{pH}$ was attributed to the decrease of the osmotic pressure. Between the carboxylic groups of PAS and the ionized groups of medium appear the repulsion forces which reduce the osmotic pressure allowing the solvent molecules to penetrate the network meshes and thus increasing the polymers swelling capacity. 

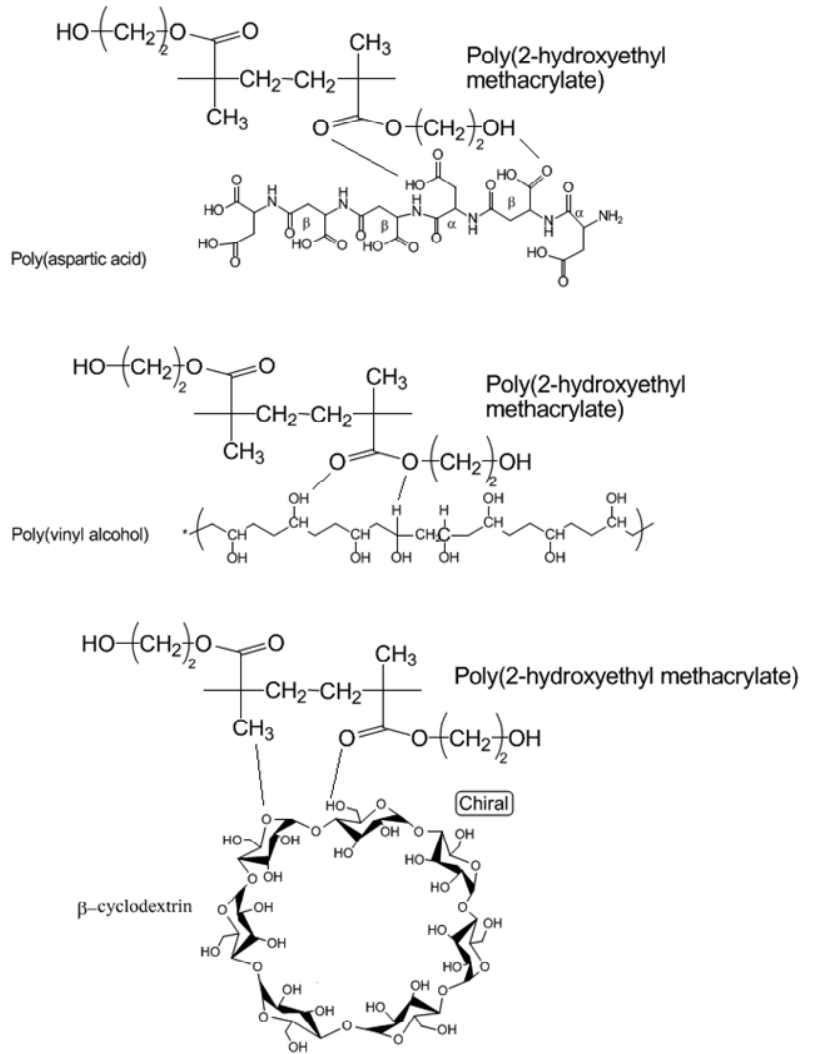

Figure 5. Illustration of the chemical structures involved in the polymerization processes.

\subsection{The Evaluation of the Drug Homogeneity into Polymeric Matrices}

PAS, CD and PVA were used during pHEMA synthesis not only for their character as protective colloids but as well to improve the ability of the homopolymer for coupling bioactive compounds and to control the drug release in biological medium [16]. Near-infrared chemical imaging (NIR-CI) was used as non-destructive method, to evaluate the distribution of indomethacin (INN) in the synthesized polymeric samples. The method represents a challenging combination for visualizing the spatial distribution and homogeneity of drug accompanied with chemometrics tools and image-processing method [17]. Evaluation of drug loading degree and indomethacin/polymeric system homogeneity was estimated by PLS-DA (Partial least squares-Discriminant Analysis). Figure 6 illustrates the score images derived from the indomethacin component class. In the score images, the pixels with higher and lower score values are indicated by light gray and dark code colors, respectively. For the polymeric network loaded with indomethacin, the code color in the most region of the score images is gray, the intermediate color between light gray (the cod color of the polymers) and dark gray colors (the code color of indomethacin). The predominantly gray score images evidences the homogeneity distribution of drug in the synthesized polymeric matrices. Also, the code color attests the qualitative differences between the polymeric networks variants loaded with drug.

\subsection{In Vitro Controlled Release of Indomethacin}

As it is well known the physicochemical properties of the polymeric network as well as the drug loading method determine the further release mechanism of the bioactive product [18]. The release profiles of INN from the polymeric loaded samples, in physiological buffer solution $\left(\mathrm{pH}=7.4\right.$, and $\left.37^{\circ} \mathrm{C}\right)$ are presented in Figure 7. For all polymer/INN complex formulations (Figure 8), the sus-

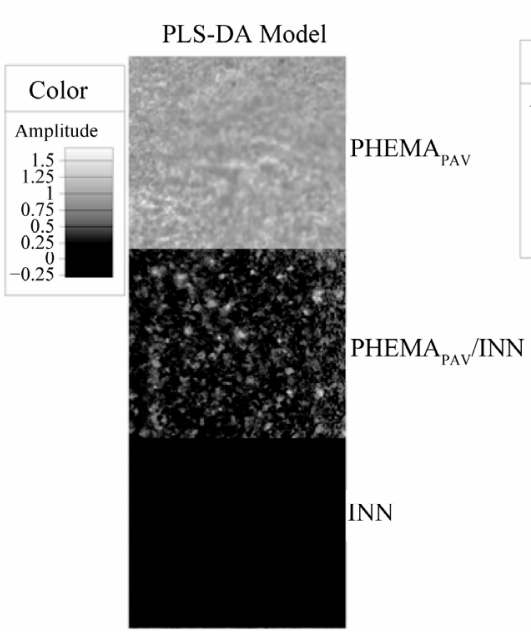

(a)

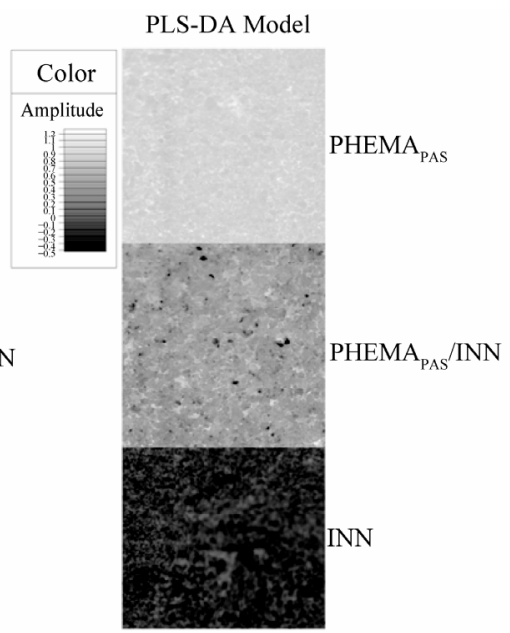

(b)

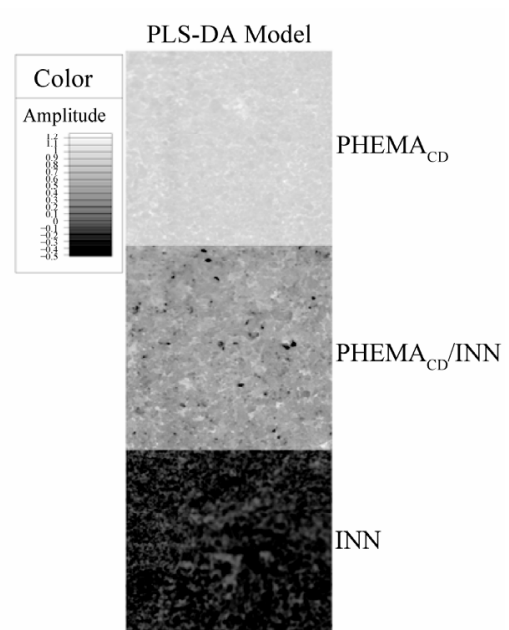

(c)

Figure 6. Score images of the indomethacin inclusion into the polymeric networks PHEMAPVA (a); PHEMA PHEMA $_{\text {CD }}$ (c). 


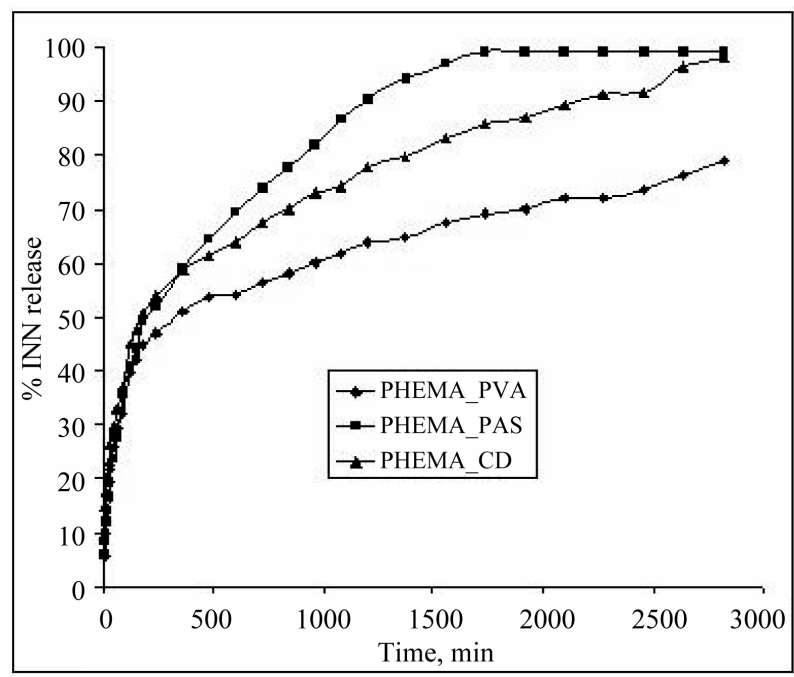

Figure 7. The INN releasing profile from the polymeric matrices.

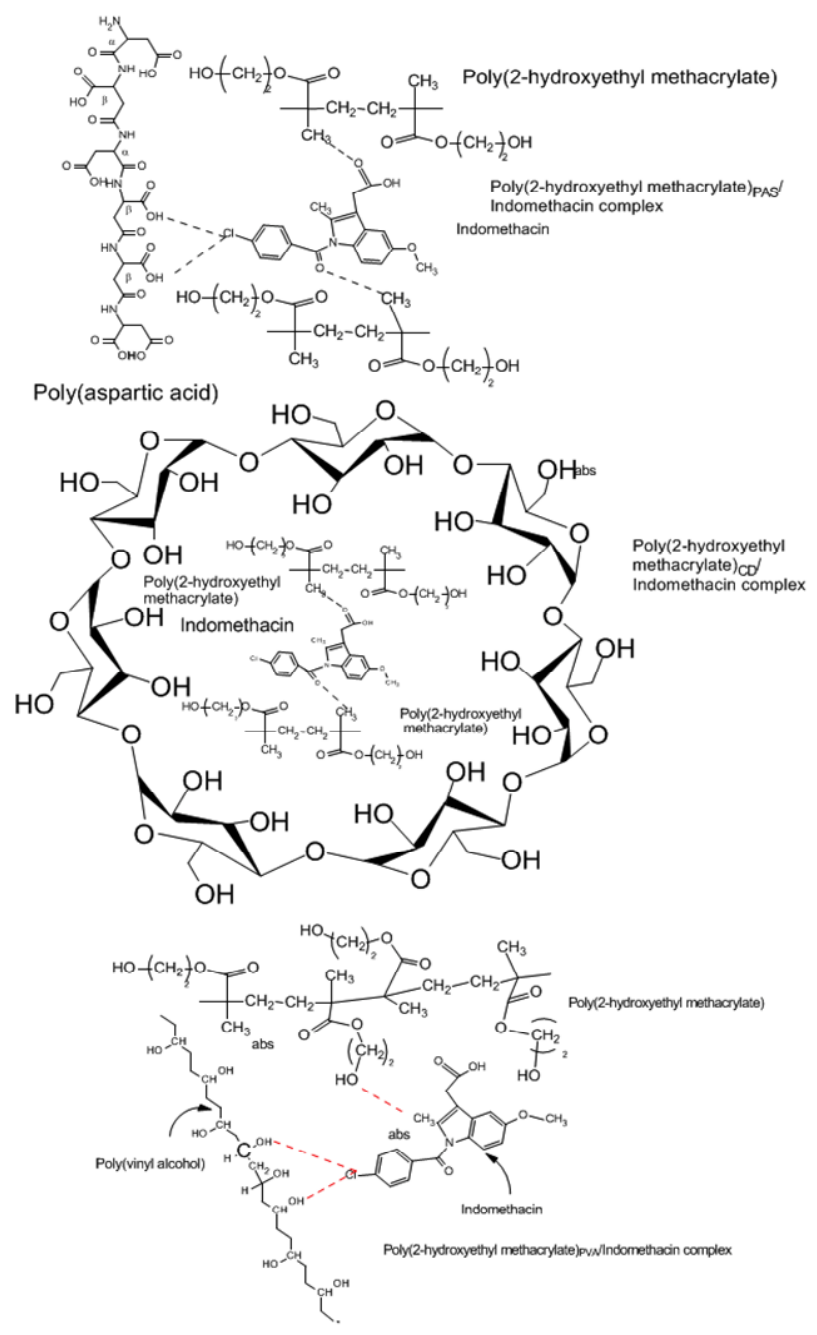

Figure 8. Illustration of the poly(2-hydroxyethylmethacrylate)/INN complex formation. tained release behavior was observed. During the first 300 minutes, all samples present a faster release of INN (burst effect). The burst release is owing to the presence of the drug at the surface of the polymeric particles. After this interval of time the release kinetic is slowed, behavior which is attributed to the links intervened between drug and the protective colloid. Thus, pHEMA ${ }_{\mathrm{PAV}}$ samples present the slowest release rates, while the $\mathrm{pHEMA}_{\mathrm{CD}}$ and pHEMA $_{\text {PAS }}$ samples are releasing much faster the drug. This aspect is sustained as well by the largest pores of pHEMA $\mathrm{PAV}_{\mathrm{P}}$ (Figure 3) which can keep and maintain the drug inside the network, and not only at surface as in case of $\mathrm{pHEMA}_{\mathrm{CD}}$ and $\mathrm{pHEMA}_{\mathrm{PAS}}$ samples. And more then that PHEMA $_{\mathrm{PAV}}$ have the lowest swelling degree which may explain as well this slowest release. The entire quantity of loaded indomethacin was released from pHEMA $_{\mathrm{PAS}}$ and $\mathrm{pHEMA}_{\mathrm{CD}}$ samples during the time of observation, while just $79 \%$ of drug was released from PHEMA $_{\text {PAV. }}$

\section{Conclusion}

The study evidences the possibility of using poly(vinyl alcohol), $\beta$ cyclodextrin or poly(aspartic acid) as protective colloids for the preparation of poly(2-hydroxyethyl methacrylate) through radical processes of polymerization. FTIR spectra confirm the synthesis of pHEMA as well as the presence of PVA, CD or PAS. The influence of the protective colloids was put into evidence by the different behaviors of the synthesized homopolymers during thermal decomposition. Thus, polymers can be ranked in the following order of their thermal stability: pHEMA $_{\text {PAV }}>$ pHEMA $_{\text {PAS }}>$ pHEMA $_{\mathrm{CD}}$, behaviour justified by the increased numbers of hydrogen bonds intervened between the molecular chains and related to the molecular weights of the protective colloids. The shape and morphology of the pHEMA structure were found to be the effective result of the used protective colloids. Therefore, complementary SEM observations evidenced the role played by the surfactants: the particles are changed from irregular aggregates in the case of using PVA, to well-defined filaments in the case of PAS, or tracery when $\mathrm{CD}$ is used. The swelling capacity is also depending on the protective colloids variant used during pHEMA synthesis. Thus, the swelling degree of the polymers is growing in the following order: pHEMA $_{\mathrm{PAV}}<\mathrm{pHEMA}_{\mathrm{CD}}$ $<$ pHEMA $_{\text {PAS }}$. The behavior was justified by the core/ shell structure of the PHEMA micelles with 1) the hydrophobic segment of PAV shell oriented on the exterior of the micelle surface, as well as 2) the superabsorber character of PAS and 3) hydrophilic nature of CD. The synthesized pHEMA particles were used as matrix for coupling indomethacin as model drug. The NIR-CI me- 
thod confirmed the homogeneous distribution of the INN in the polymeric network. The INN release was also dependent on the protective colloids variant used for the pHEMA preparation. Thus, pHEMA $A_{\mathrm{PAS}}$ as well as pHEMA $_{C D}$ matrices release almost the entire quantity of the coupled INN. During the same period of releasing time, pHEMA $_{\mathrm{PAV}}$ retains amounts of drug, behaviour justified by the morphology of the particles, higher molecular weight of PAV, and the hydrophobic surface of the core/shell pHEMA particles.

\section{Acknowledgements}

This work was financially supported by the grant of the Romanian National Authority for Scientific Research, CNCS-UEFISCDI, project number PN-II-211/2012 "Interdisciplinary research on multifunctional hybrid particles for bio-requirements".

\section{REFERENCES}

[1] G. Mabilleau, C. Cincu, M. F. Basle and D. Chappard, "Polymerization of 2-(Hydroxyethyl Methacrylate by Two Different Initiator/Accelerator Systems: A Raman Spectroscopic Monitoring," Journal of Raman Spectroscopy, Vol. 39, No. 7, 2008, pp. 767-771. http://dx.doi.org/10.1002/jrs.1960

[2] J. P. Montheard, J. Kahovec and D. Chappard, "Chapter 5," In: R. Arshady, Ed., Desk Reference of Functional Polymers; Syntheses and Applications, American Chemical Society, Washington DC, 1997, pp. 699-750.

[3] J. Barton and I. Capek, "Radical Polymerization in Disperse Systems," Ellis Horwood, New York, 1994.

[4] R. G. Gilbert, "Emulsion Polymerization: A Mechanistic Approach," Academic Press, London, 1995.

[5] R. M. Fitch, "Polymer Colloids: A Comprehensive Introduction," Academic Press, London, 1997.

[6] C. S. Chern, "Emulsion Polymerization Mechanisms and Kinetics," Progress in Polymer Science, Vol. 31, No. 5, 2006, pp. 443-486.

http://dx.doi.org/10.1016/j.progpolymsci.2006.02.001

[7] A. P. Chiriac, L. E Nita and M. T. Nistor, "Copolymerization of 2-Hydroxyethyl Methacrylate with a Comonomer with Spiroacetal Moiety," Journal of Polymer Science Part A: Polymer Chemistry, Vol. 49, No. 7, 2011, pp. 1543-1551. http://dx.doi.org/10.1002/pola.24575

[8] H. H. Chu and C. S. Lin, "The Effect of Initiators on the Emulsion Polymerization of 2-Hydroxyethyl Methacrylate," Journal of Polymer Research, Vol. 10, No. 4, 2003, pp. 283-287.

http://dx.doi.org/10.1023/B:JPOL.0000004631.64826.3c

[9] S. Rimmer, P. Tattersall, "The Inclusion of $\beta$-Cyclodextrin Provides a Supramolecular Solution to the Problem of Polymerization of Dodecyl and Octadecyl Methacrylates in Aqueous Emulsion," Polymer, Vol. 40, No. 20, 1999, pp. 5729-5731.

http://dx.doi.org/10.1016/S0032-3861(99)00139-1

[10] T. Sun, J. Shen, H. Yan, J. Hao and A. Hao, "Stable Vesicles Assembled by 'Supramolecular Amphiphiles' with Double Hydrophobic Chains," Colloids and Surfaces A: Physicochemical and Engineering Aspects, Vol. 414, 2012, pp. 41-49.

http://dx.doi.org/10.1016/j.colsurfa.2012.08.045

[11] Y. Hou, F. Xin, M. Yin, Li Kong, H. Zhang, T. Sun, P. Xing and A. Hao, "Stimuli-Responsive Supramolecular Organogels That Exhibit a Succession of Micro-Morphologies," Colloids and Surfaces A: Physicochemical and Engineering Aspects, Vol. 414, 2012, pp. 160-167. http://dx.doi.org/10.1016/j.colsurfa.2012.08.011

[12] L. E. Nita, A. P. Chiriac, S. Cimmino, C. Silvestre, D. Duraccio and C. Vasile, "Polymerization in Magnetic Field. Influence of Surfactant Nature on the Polymerization Reaction and on Thermal Properties of PMMA and MMA-Co-GMA Copolymers," Polymer International, Vol. 57, No. 2, 2008, pp. 342-349. http://dx.doi.org/10.1002/pi.2355

[13] A. P. Chiriac, L. E. Nita, I. Neamtu and M. Bercea, "Contribution to Polymer Nanoparticles Analysis by Laser Light Scattering," Polymer Testing, Vol. 28, No. 8, 2009, pp. 886-890. http://dx.doi.org/10.1016/j.polymertesting.2009.08.003

[14] L. E. Nita, A. P. Chiriac, C. M. Popescu and I. Neamtu, "Possibilities for Poly(Aspartic Acid) Preparation as Biodegradable Compound," Journal of Optoelectronics and Advanced Materials, Vol. 8, No. 2, 2006, pp. 663666.

[15] L. X. Song, C. F. Teng, P. Xu, H. M. Wang, Z. Q. Zhang and Q. Q. Liu, "Thermal Decomposition Behaviors of $\beta$-Cyclodextrin, Its Inclusion Complexes of Alkyl Amines, and Complexed $\beta$-Cyclodextrin at Different Heating Rates," Journal of Inclusion Phenomena and Macrocyclic Chemistry, Vol. 60, No. 3-4, 2008, pp. 223-233. http://dx.doi.org/10.1007/s10847-007-9369-1

[16] J. F. R. Santos, R. Couceiro, A. Concheiro, J. J. T. Labandeira and C. Alvarez-Lorenzo, "Poly(Hydroxyethyl Methacrylate-Co-Methacrylated- $\beta$-Cyclodextrin) Hydrogels: Synthesis, Cytocompatibility, Mechanical Properties and Drug Loading/Release Properties," Acta Biomaterialia, Vol. 4, No. 3, 2008, pp. 745-755. http://dx.doi.org/10.1016/j.actbio.2007.12.008

[17] Z. Wu, O. Tao, W. Cheng, L. Yu, X. Shi and Y. Qiao, "Visualizing Excipient Composition and Homogeneity of Compound Liquorice Tablets by Near-Infrared Chemical Imaging," Spectrochimica Acta Part A: Molecular and Biomolecular Spectroscopy, Vol. 86, 2012, pp. 631-636. http://dx.doi.org/10.1016/j.saa.2011.10.030

[18] C. C. Lin and A. T. Metters, "Hydrogels in Controlled Release Formulations: Network Design and Mathematical Modeling," Drug Delivery Reviews, Vol. 58, No. 12-13, 2006, pp. 1379-1408. http://dx.doi.org/10.1016/j.addr.2006.09.004 